\title{
BRODER GIOVANNI OCH JUDARNA
}

\author{
Karmela Belinki \\ Helsingfors
}

\begin{abstract}
A в S T R A C T This paper deals with the portrayal of the Jew in a Finnish comic magazine edited by the pseudonym Veli Giovanni (Brother Giovanni) for more than thirty years (1919-1950). The stereotypical and negative image of the Jew hardly changed from the very first issue to the last. There were caricatures of the Jew in almost every issue of the magazine. Because of its popularity it was probably not completely without influence, although it claimed to be innocent entertainment and did not confess to any political attachment. The physiognomy of the Jew follows the classical pattern (big nose, curly hair, short body). The character is congruent with the body. The Jew is a slimy figure, constantly trying to cheat others. He is greedy and his main interest is money. He is an internationalist, a non-patriot, and he speaks Finnish with a strange accent and using his own idiolect (Jewish gibberish). He is the total opposite of the real Finn and an alien in Finnish society. The son of the Jew is the adult in miniature.
\end{abstract}

Den offentliga Bilden AV Juden har förblivit negativ allt från Nya Testamentet till islamisk dagspolitik. Juden har pålagts fysiska och mentala karakteristika, som utvecklats till stereotyper och dessa har upprepats genom medeltida skräckhistorier, inkvisitionens propaganda, tudortidens dramatik, franska revolutionens och napoleontidens litteratur, tysk 1800 -tals dramatik och romaner, Hitlers propaganda till Martin Walsers nyaste böcker och genom rysk klassisk 


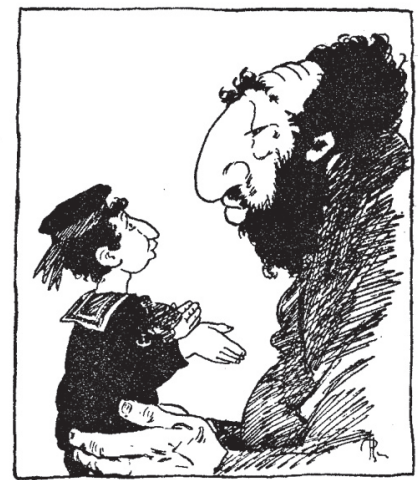

»Ishä, migä on turhhamaisuutta?»

»Turhhamaisuutta on pite gaulust, kun olemas gokobarta.»
„Far, vad är fåfängt?»

„Fåfängt är att ha krage, när man har helskägg.»

litteratur och Stalins antisemitiska propaganda till det nya Rysslands antisemitiska skriverier. I inledningen till min bok Shylock i Finland. Juden och Finlands litteratur 1900-1970 talar jag om Shylock-fenomenet $^{1}$.

I min bok undersökte jag bilden av juden i finländsk litteratur. Min slutsats var, att judar förekommer i Finlands litteratur endast marginellt. Det finns ingen egen finsk stereotyp bild av juden. De få exemplen är utländska lån.

Litteraturen och skämttidningarna är avlägset besläktade. Där litteraturen som bäst strävar efter fördjupande presentation och debatt är skämttidningen en dagslända som stångas med aktuella frågor. Till skämttidningens profil hör tillspetsning, sarkasm och ironi. Skämttidningarna har jämfört med litteraturen en tilläggsdimension i bilden, teckningen. Den mesta kända skämttidningen är säkert den engelska Punch, som långt utgjort en förebild för andra. Kvinnobilden i Punch har undersökts av Constance Rover i boken The Punch Book of Women's Rights. Finska skämtteckningar har senast undersökts av Marja Ylönen, vars Pilahistoria. Suomi poliittisissa pilapiirroksissa 1800-luvulta 2000-luvulle utkom 2001.

Efter att ha avslutat ovan nämnda arbete fick jag tanken på att fortsätta med finska skämtteckningar. Mina förebilder var Lars M. Anderssons forskning om judarna i svensk skämtpress 1900-1930 och 
Judith Vogts två verk om antisemitismen och antisionismen i karikatyrer samt om bilden som ett politiskt vapen. Jag mindes, att min far nämnt en skämttidning utgiven av Veli Giovanni (Broder Giovanni), som han i sin ungdom påträffat och som han ansåg vara synnerligen antisemitisk. Denna skämttidning Pilajuttuja ja piirroksia: koti- ja ulkomaista huumoria utgiven av pseudonymen Veli Giovanni alias H.J. Viherjuuri utkom i över trettio år 1919-1950.

\section{Veli Giovannis skämttidning som fenomen}

Veli Giovannis skämttidning var ett barn av sin tid, som överlevde sin egen tid. Dess tematik var enkel och den vädjade till läsarnas fördomar och föreställningar. Den utkom i tre decennier utan större förändringar i innehållet och upprepande de första tidernas motiv, under sin glansperiod en gång i veckan. Bara bilderna avspeglade epokskiftena. Veli Giovannis tidning hade ingen politisk dimension, som Punch, och den personifierade inte sina objekt. Den talade om judar och andra kollektivt, alldeles som om hade alla gruppens medlemmar varit identiska. Det förekommer ingen större skillnad i antalet judebilder. Judevitsar förekommer i så gott som alla nummer som en jämn ström, ibland flera i samma nummer, men man kan inte tala om någon systematik. Veli Giovannis skämtteckningar och vitsar ansågs antagligen harmlösa för att de saknade intellektuell satir. Tidningen stärkte dock den s.k. allmänna opinionen. Den i finländska förhållanden långvariga utgivningsperioden visar på både seghet och också popularitet. Den var populär, men i ännu högre grad populistisk.

\section{Finländares uppattning om judarna}

Eftersom finländarnas uppfattning om judarna inte nämnvärt undersökts är alla påståenden endast åsikter. En fingerspetskänsla och över ett halvt sekels praktisk erfarenhet samt flera generationers släkttradition följer de empiriska slutsatserna i min Shylock-bok om litteraturen, att finländarnas uppfattning om judarna inte är strukturellt negativ. Individuella skillnader finns självfallet och antagligen skillnader mellan de olika samhällsgrupperna och mellan stad och land.

Professor Aira Kemiläinen berättar i ett privatbrev som tillägg till sin självbiografi Toisen maailmansodan paineessa hur hon som lek- och skolkamrat i Helsingfors hade en judisk flicka, som inte på 
något sätt segregerades i kamratkretsen. De flesta finländare hade aldrig träffat judar för att de var så få i Finland och fanns bara i de stora städerna. På något sätt hade man i varje fall en negativ åsikt om judarnas handelsvanor, skriver professor Kemiläinen. Det är möjligt att judiska handelsmän från Ryssland införde annorlunda seder, och ryssar var inte precis omtyckta. ${ }^{2}$ Det styrker förklaringen om judejargongen och Veli Giovannis grundkarikatyr om judarna som baksluga handelsmän.

\section{Judebildens huvuddrag}

Jämfört med Anderssons material är Veli Giovanni mera primitiv och enklare. Anderssons grundindelning i judens fysiska apparition och judiskt penningbegär är dock användbar också i fråga om Veli Giovanni. Däremot är Anderssons tredje grundelement judarnas smygande intrång i samhällets olika sfärer svårare att tillämpa på Veli Giovannis objekt. Till judarnas fysionomi hör också judarnas karaktär. I hundratals skämtteckningar tecknas juden inte en enda gång positivt. Inte ens situationen efter andra världskriget, då man även i Finland var medveten om de europeiska judarnas öde, för med sig någon ändring i den allmänna bilden. Veli Giovanni uttrycker med anledning av tidningens trettio år 1949, att tidningens vitsar är oskyldiga jämfört med de godbitar som den prisbelönta moderna finska litteraturen innehåller. ${ }^{3}$ Ändå kallar han i nästa andetag juden vid öknamn då han berättar en gammal judevits.

\section{Judens fysionomi och kroppspråk}

Judens fysionomi följer klassiska antisemitiska drag. Juden har böjd näsa och rygg, han är i allmänhet kortväxt och har stor mage, han ser motbjudande och listig ut med sina utstående ögon. Håret är antingen lockigt och mörkt eller så är han skallig. Objektet för skämtteckningarna är i allmänhet den judiska mannen. Mannens son liknar sin far, men i miniatyr.

Främlingskapet styrks med att beskriva juden som gestikulerande med händerna, varav det finns flera exempel, bl.a. i band 63/1924 s. 58: Den unge Isaskar är för första gången på konsert med sin far. När han ser kapellmästaren gestikulera med händerna, frågar Isaskar: Far, far, med vem talar den där farbrorn. I det här sammanhanget är det omöjligt att delge den speciella finsk-judiska jargong, 
som genomgående förekommer i vitsarna och som förklaras i huvuddrag i det följande.

En skämtteckning i band 12/1920 s. 15 gör narr av judens näsa. Titeln lyder I zoologiska trädgården. Far, far! Där är storken, som hämtar judebarn. Storken har en böjd näbb som påminner om judens näsa. Ett mycket grövre exempel utkom i band 146/1931 på s. 56: I ridskolan. Läraren: upp med mulen, herr Goldstein. Goldstein lyfter huvudet. Läraren: Mulen upp!. Goldstein lyfter huvudet ännu högre. Läraren: Upp med hästens mule, hör ni inte. Jag sade ingenting om snabeln.

\section{Judens språk}

I min bok behandlade jag det scenspråk som skapades för judar (ty. Bühnenjüdisch, eng. Jewish gibberish), med vilket man poängterar judens främlingskap. Det är landets språk med brytning, men så speciellt, att man omedelbart begriper, att det tillhör judarna. Veli Giovannis judar talar ett slags bruten judisk finska, som inte ändras under tidens lopp. I Veli Giovannis judiska finska är brytningen både av ryskt och diffust kanske också av svenskt, tyskt eller jiddiskt ursprung. Det ryska kan man historiskt förklara med att de flesta finländska judar kom från det ryska Baltikum eller Vitryssland. A andra sidan tyder den på finnarnas traditionella motstånd mot det ryska. Svenskans inflytande förklaras med fennomanin, vars grundtanke var enspråkighet. Tyskans inflytelse går tillbaka till judarnas modersmål jiddisch, som grundar sig på medeltida tyska. Det är att märka, att under den period då Veli Giovannis tidning utkom talade de flesta judar i Finland redan landets språk felfritt.

\section{Judarnas sätt och karaktär}

Redan i det första bandet år 1919 förekommer flera judevitsar. Den första på sidan 5 gör narr av svinköttsförbudet i judendomen och judarnas vilja att bryta mot det. Det går kanske redan tillbaka till urkristna icke-judars iver att fjärma kristendomen från judendomen genom att ogilla judiska traditioner och lagar och genom att anse Jesu läror unika. Nahum Haggaisohn har beställt en griskotlett på restaurang, då plötsligt ett oväder uppstår. Just när Nahum har fått ned kotletten, slår blixten ned med förfärlig styrka. Nahum: Det var nu ett rysligt oväsen för en liten fläskbit. Detta uttalas med 
den distinkta judiska brytningen. I denna första skämtteckning har judens fysiska apparition ännu inte antagit den form som blev typisk redan i följande teckning i samma band.

I band 17/1921 förekommer en vits med samma andemening som ovan. På sidorna 16-22 finns en serie under rubriken Om man hade haft reklam på Gamla testamentets tid. Publikens anletsdrag är judiska och tonen i skämtteckningarna nedsättande. Det var på utgivarens tid populärt att anse att Gamla Testamentet var judarnas Bibel, medan för de kristna GT:s värde bestäms i förhållande till Nya Testamentet. För de kristna innebär GT endast en introduktion till NT. Eftersom judarna inte accepterar NT:s grundbudskap om Jesus som Messias har därmed GT ett egenvärde endast för judarna och får därför ringaktas som judarnas bok I enlighet med sin grundkaraktär är judarna inte trogna ens sin egen bok.

Märkvärdig är föreställningen om judarna som smutsiga, som kanske går tillbaka till en medeltida myt. Den förekommer i olika former i flera skämtteckningar. Band 76/1925 s. 57: Jonathan Levizohn är vald till fullmäktige. Det kommer ett förslag, som Jonathan skarpt motsätter sig och han säger till slut med eftertryck (med judisk brytning): Gör vad ni gör, jag tvättar händerna. Äntligen, hörs en röst ur leden.

I det nyligen självständigförklarade Finland är antipatriotism en aktuell fråga. Finland genomgick 1918 ett självständighetskrig, som innebar i praktiken ett inbördeskrig mellan »vita» och »röda». Judarna föraktades både av de röda som illojala mot socialismen och arbetarnas nya Ryssland och av de vita som inte tillräckligt nationalistiska och som potentiella spioner för den högstbjudande. Det var dock bara ekon av det som förekom i Ryssland och andra östeuropeiska länder både före och efter första världskriget. Judarna som internationalister (ett förhatligt ord) var gemensamt för de antijudiska rörelserna. I band 24/1921 s. 5 står en jude med en rysk orden. Han har fătt den i kriget efter att ha erövrat fiendens flagga i en skärmytsling. Inspekterande generalen: Berätta hur du egentligen lyckades. Juden (f.d.fanbärare): Herr General, där fanns en jude också på fiendesidan och vi bytte flaggor. Detta uttalas med påfallande judisk brytning.

Juden som ynkrygg är temat i 1925/83 s. 61: I den polska armén: 1. Isaskar Abrahamsson har blivit inkallad. Isaskar placeras vid den ryska gränsen för att passa på fienden. 2. När en officer kommer på inspektion, ser han Isaskar under kullen bakom en stor sten. Isaskar 
»Hämta något sådant så folk ser att jag är en fin herre.»

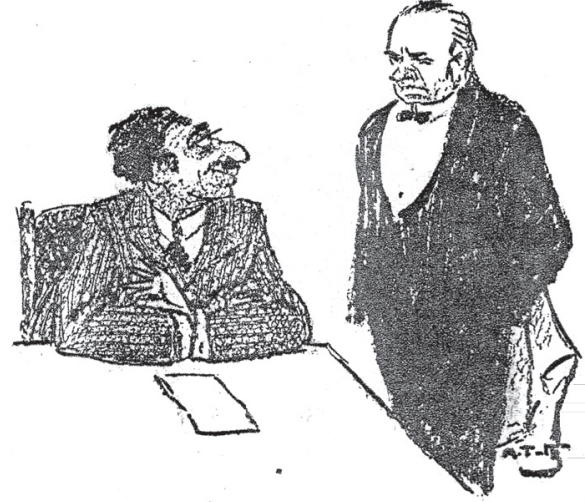

》Tuokaa minulle jotakin shellaist ruoga, ett ihmishe neke et mine on hieno miäs.»

försvarar sig med: Jag hatar bolsjevikerna så mycket att jag överhuvudtaget inte vill se dem.

Den judiska uppkomlingen förekommer i flera vitsar, såsom t.ex. i 155/1932 s. 12: I restaurangen: Josef Kirshbaum till kyparen: Hämta något sådant så folk ser att jag är en fin herre. Liknande finns i 158/1932 s. 30: Bibelförklaring: Lilla Kalle: Säg far, hur kunde Jona komma in i valens mage. Far: Vet du inte, att judarna kryper överallt. Här används självfallet vanligt språkbruk. Det är fråga om finnar som talar om judar.

\section{Temat juden och pengar - usurpation som kult och mammon som gud}

Andersson säger i sin bok, att en stor del av skämtpublikationernas judevitsar handlar om judarnas girighet och snålhet, judarnas lidelsefulla attityd till affärsverksamhet och ekonomisk vinning samt judarnas oförmåga att tänka på annat sätt än ur affärssynvinkel.

Genom ett visuellt och verbalt kodsystem skapar man judens genetiska karaktär. Den som ser judisk ut talar som en jude och kan tänka enbart judiskt, dvs. i ekonomiska termer. Juden blir inkarnationen för mammon. ${ }^{4}$

Resultatet av karaktärsanalysen är för den stereotypa judebilden enspårigt negativ. Judens mest markanta drag är kärleken till pengar. 
Huvudtemat för Veli Giovannis skämtteckningar är juden och pengar i olika varianter. Som exempel på upprepning må tjäna ett band från varje utgivningsdecennium av Veli Giovanni.

Redan i det första bandet år 1919 på sidorna 21 och 41 finns två vitsar med temat juden och vinsttänkandet. I den första visar juden ett tyg och säger med judebrytning: Det här är mycket vackert och kostar bara $5 \mathrm{mk}$ metern. Men frånsidan är ju mycket vackrare. Tja, men den är dyrare, kostar $7 \mathrm{mk}$ metern. I den andra är läkaren hos en judisk patient: Patienten (jude): Tar ni tjugo mark för ett sjukbesök? Läkaren, Ja, det brukar jag. Patienten: Men jag har ju utbrett min sjukdom i hela den här stadsdelen!

I 1925/83 förekommer flera vitsar över temat. På sidan 60 beskrivs hur en finne, en svensk, en tysk och en jude är på restaurang. När de stigit ut säger finnen: Såg du vilken fin silveraskkopp där fanns? Svensken: Man kunde ha tagit den. Tysken: Jag tog den. Juden: Jag såg att du tog den och jag tog den ifrån dig och sålde den till en herre, som steg in i restaurangen. Det är att märka, att alla de övriga talar på vanligt sätt, medan juden använder sin egen rotvälska.

Också i band 115/1932 behandlas den judiska affärsmannen i flera vitsar. S. 46: Dåligt tecken. Moses: Vår Sebulon blir ingen bra affärsman. Sara: Det är ju hemskt - vad har han nu igen gjort? Moses: När jag idag sade åt en kund att tyget var äkta prima engelsk ull, så rodnade skurken Sebulon.

Under andra världskriget utkom Veli Giovannis tidning bara sporadiskt. I band 175/1943 fanns det rum för två judevitsar på s. 25. Man ber om en donation av Moses Goldenbaum. Moses blir förvånad och slår ut med armarna: Vad vill ni av mig. Jag har ju gett redan så mycket. Läser ni inte tidningen. Igår stod det: Okänd donerat $10000 \mathrm{mk}$, idag står det: Okänd donerat $20000 \mathrm{mk}$. Vet ni inte, att jag är denna stora okända.

\section{Resumé}

Andersson poängterar judebilden i skämtpressen som en rastyp och judarna som en ras. ${ }^{5}$ Denna slutsats äger också riktighet i fråga om Veli Giovannis skämtteckningar. Juden beskrivs som en avvikande finne både till fysionomin och till karaktären. Juden talar den för judar typiska finsk-judiska rotvälskan. Speciellt framhävs näsan i judens anletsdrag. Det allmänna intrycket är lömskt och motbjudande. Till karaktären är juden ofinsk med listighet, ohederlighet 
»Hur har du fătt dina

stora pengar.»

"Jag hade en rik bekant.

Han hade pengarna, jag erfarenheten. $\mathrm{Nu}$ har jag pengarna - han erfarenheten.»

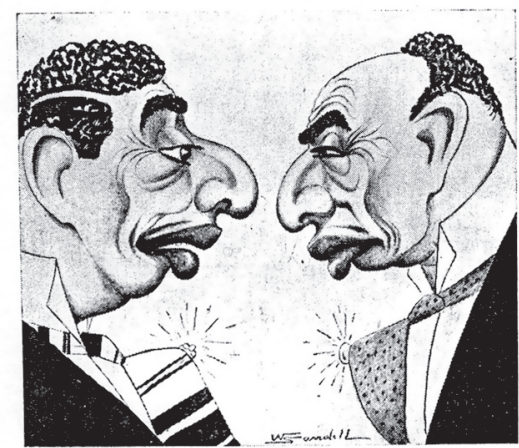

»Miten shine ole shaanu shinu shuure rahasi?» »Minul oli yks rikas tuttava. Hänel oli raha, minul kokemus. Nyt o minul raha, - ja hänel kokemus!»

och slughet samt mammonsdyrkan som grundtypiska drag. Han är olik finnarna till lynnet och kroppsspråket. Hans smutsighet är enligt Andersson urban smuts i motsats till bondens hederliga jordbundna smuts. Detta motsatsförhållande förekommer dock inte hos Veli Giovanni och judarnas smutsighet kunde kanske hellre anknytas till medeltida myter om judarnas religiösa riter. Juden är internationalist och därmed en dålig patriot. Allt som allt är judarna i Veli Giovannis tidning osympatiska, främmande väsen i det finska själsliga landskapet och i det finska samhället.

Enligt Andersson har skämtpressens judebild föga påverkat judarnas integrering i det svenska samhället. Detsamma kan man säga om Veli Giovannis skämttidning. Helt kan man dock inte bortse från dess inverkan och betydelse. Dess bild av juden är inte unik, inte heller den första i sitt slag - knappast heller den sista. Vrångbilder har en tendens att motstå försök att korrigera dem.

\section{Noter}

1. Bélinki 2000, 11

2. Aira Kemiläinens brev till författaren, daterat 2.2.2002

3. Veli Giovanni 1949, No 1 (189), 1

4. Andersson 2000, 171

5. Andersson 2000, 473 


\section{Litteratur}

Andersson, Lars M, 2000, En jude är en jude är en jude... Representationer av juden i svensk skämtpress omkring 1900-1930, Nordic Academic Press

Bélinki, Karmela, 2000, Shylock i Finland. Juden och Finlands litteratur 1900-1970, Religionsvetenskapliga skrifter 53, Åbo Akademi

Kemiläinen, Aira, 2000, Toisen maailmansodan paineessa, Helsinki: SKS

Rover, Constance, 1967, The Punch Book of Women's Rights, London: Hutchinson

Veli Giovanni (H.J.Viherjuuri),1919-1950, Pilajuttuja ja piirroksia: koti- ja ulkomaista huumoria, Helsinki

Vogt, Judith, 1978, Antisemitisme og antisionisme i karikaturer, Köbenhavn: Reitzel/ Cappelen

Vogt, Judith, 1988, Billedet som politisk våben, Köbenhavn: Reitzel/Cappelen

Ylönen, Marja, 2001, Pilahistoria. Suomi poliittisissa pilapiirroksissa 1800-luvulta 2000luvulle, Helsinki: SKS 